\title{
POTENSI WISATA DAN PREFERENSI VISUAL LANSKAP WISATAWAN UNTUK PENGEMBANGAN PARIWISATA PESISIR (KASUS : PANTAI ANGIN MAMIRI DAN TANJUNG BAYANG KOTA MAKASSAR)
}

\author{
Feri Fadlin ${ }^{1}$, Muh. Aris Marfai ${ }^{2}$, dan Andri Kurniawan ${ }^{3}$
}

Fakultas Geografi, Universitas Gadjah Mada, Yogyakarta, Indonesia ${ }^{1,2,3}$ ferifadlin@gmail.com

Diterima : Maret 2015; Direvisi : Juni 2015.; Dipubikasikan: Maret 2016

\begin{abstract}
ABSTRAK Penelitian ini bertujuan untuk (1) menganalisis potensi dan kondisi sumberdaya untuk kesesuaian dan daya dukung kawasan wisata pesisir, (2) menganalisis kondisi sosial ekonomi masyarakat pesisir kawasan wisata, (3) menganalisis preferensi visual lanskap wisatawan terhadap estetika kawasan wisata dan (4) menyusun strategi pengembangan kawasan Pantai Angin Mamiri dan Tanjung Bayang Kota Makassar. Penelitian ini menggunakan metode survei dan studi literatur untuk mengumpulkan data primer dan data sekunder. Teknik analisis data menggunakan pendekatan kuantitatif maupun kualitatif. Pendekatan kuantitatif digunakan dalam analisis Indeks Kesesuaian Wisata, Daya Dukung Kawasan, Jejak Ekologis Wisatawan dan Estimasi Estetika Lanskap. Pendekatan kualitatif digunakan dalam analisis kondisi sosial ekonomi masyarakat dan analisis SWOT untuk menyusun strategi pengembangan kawasan wisata. Hasil penelitian menunjukkan bahwa indeks kesesuaian wisata pesisir pada Pantai Angin Mamiri termasuk kategori sangat sesuai (S1) dan Pantai Tanjung Bayang kategori sesuai (S2). Nilai daya dukung kawasan masih potensial dikembangkan. Jejak ekologis wisatawan menunjukkan nilai tertinggi pada komponen makanan, kemudian transportasi, akomodasi dan sampah. Tingkat pendidikan dan penghasilan masyarakat pelaku wisata masih rendah dan sebagian besar merupakan penduduk sekitar. Preferensi Visual Lanskap wisatawan menunjukkan nilai yang rendah hingga sedang pada lanskap dengan komponen non alami dan alami serta tinggi pada tutupan lahan dengan komponen alami. Rekomendasi strategi pengembangan obyek wisata yaitu pemanfaatan potensi sumberdaya alam dan lingkungan wisata secara optimal, dan mengoptimalkan kerjasama antara Lembaga Pemberdayaan Masyarakat (LPM) Tanjung Merdeka dan Pemerintah dalam pengelolaan limbah, peningkatan aksesibilitas serta pembangunan sarana prasarana wisata dengan tetap memperhatikan kelestarian dan kebersihan lingkungan pantai.
\end{abstract}

Kata kunci: jejak ekologis; potensi wisata; preferensi visual.

ABSTRACT This research aims to (1) analyze potency and condition of coastal resources for land suitability and carrying capacity of coastal tourism, (2) analyze socioeconomic condition of coastal community, (3) analyze tourist visual preference and (4) and arrange tourism development strategy in Angin Mamiri and Tanjung Bayang beach of Makassar. This research use survey and literature study to collect primer and secondary data. Data analysis use quantitative and qualitative approach. Quantitative approach is used to calculate Touristic Suitability Index, Carrying Capacity, Touristic Ecological Footprint (TEF) and Scenic Beauty Estimation (SBE). Qualitative approach is used to analyze socioeconomic of coastal community and SWOT analysis to arrange tourism development strategy. The result shows that touristic suitability index at Angin Mamiri beach is very suitable (S1), Tanjung Bayang Beach is suitable (S2). Carrying capacity shows that coastal tourism are enable to be developed. Touristic ecological footprint components shows the highest to the lowest value are food, transportation, accommodation and waste. Education and social income of community are in low level and most of them are from around tourism site. Tourist visual preference shows that it has low and medium values on unnatural and natural landscapes and high values on pure natural landscapes. Recommended strategies of tourism development are (1) enhancement the utilization of natural and environment tourism resources, (2) enhancement of collaboration between local government of Makassar, LPM Tanjung Merdeka and local community in waste management, enhancement of accessibility, and tourism infrastructure development which keep remark on continuity and esthetic of coastal tourism site.

Key words: ecological footprint; tourism potency; visual preference.

\section{PENDAHULUAN}

Pariwisata merupakan aktivitas multi sektor yang terkait dengan ekonomi, seni, budaya, sosial masyarakat dan lingkungan. Pembangunan di bidang pariwisata harus mempertimbangkan sektor-sektor terkait dalam perumusan kebijakan, oleh karena itu pembangunan di bidang pariwisata mensyaratkan pertimbangan ekonomi, sosial dan ekologi dalam pengembangan pariwisata yang berkelanjutan (Hall, 2001).
Pengembangan pariwisata pesisir merupakan kegiatan optimasi, interdependensi dan interaksi antar komponen sumberdaya pesisir, sumber daya manusia, dan teknologi untuk meningkatkan taraf hidup (Honey dan Krantz, 2007). Kondisi sosial ekonomi masyarakat sangat berperan dalam optimasi pemanfaatan sumberdaya pesisir. Kondisi sosial ekonomi masyarakat disatu sisi mempengaruhi pola pemanfaatan sumberdaya pesisir dalam kaitannya dengan 
pengelolaan kawasan wisata dan disisi lain pengembangan pariwisata di wilayah pesisir memberi dampak terhadap kondisi sosial ekonomi masyarakat.

Pengembangan pariwisata di Pantai Angin Mamiri dan Tanjung Bayang dirasakan belum optimal, hal ini dapat dilhat dari kondisi obyek wisata yang tampak kumuh dengan kondisi sarana prasarana yang belum memadai. Upaya pengembangan dapat dilakukan dengan mengkaji potensi sumberdaya pesisir dan aspek permintaan wisatawan. Potensi sumberdaya pesisir dapat berupa potensi sumberdaya alam, lingkungan fisik, sarana dan prasarana penunjang serta kondisi sosial ekonomi masyarakat setempat. Aspek permintaan wisatawan mencakup kebutuhan wisatawan akan lahan untuk kegiatan wisata dan preferensi terhadap kualitas estetika lanskap kawasan wisata sebagai bagian dari pengembangan daya tarik obyek wisata.

Berdasarkan uraian permasalahan tersebut maka tujuan dari penelitian ini adalah, (1) menganalisis potensi dan kondisi sumber daya pesisir kawasan wisata Pantai Angin Mamiri dan Tanjung Bayang untuk kesesuaian dan daya dukung kawasan wisata pesisir, (2) menganalisis kondisi sosial ekonomi masyarakat pesisir kawasan wisata Pantai Angin Mamiri dan Tanjung Bayang Kota Makassar. (3) menganalisis pereferensi wisatawan terhadap kualitas estetika lanskap kawasan wisata Pantai Angin Mamiri dan Tanjung Bayang dan (4) merumuskan strategi pengembangan kawasan wisata Pantai Angin Mamiri dan Tanjung Bayang yang mendukung pengembangan pariwisata pesisir berkelanjutan.

\section{METODE PENELITIAN}

Metode penelitian yang digunakan dalam penelitian ini adalah metode survei dan studi literatur. Survei merupakan penyelidikan yang dilakukan untuk menghimpun fakta-fakta dari berbagai fenomena yang ada dan menemukan informasi yang faktual baik mengenai institusi sosial, ekonomi, politik dari kelompok tertentu atau daerah yang dapat dilakukan secara sensus maupun menggunakan sampel (Goodall, 1987 dalam Yunus, 2010).

Metode survei dilakukan untuk mengumpulkan data primer sedangkan studi literatur yang relevan dengan penelitian dilakukan untuk mengumpulkan data sekunder. Analisis data sekunder dilakukan dengan menganalisis data yang sudah tersedia atau yang diperoleh dari instansi terkait. Analisa data primer dilakukan untuk mengatasi ketidaktersediaan data sekunder dan untuk memahami kondisi lokasi penelitian lebih detail.

Secara garis besar teradapat dua jenis data yang digunakan dalam penelitian ini, yaitu data spasial dan data statistik. Data spasial diperoleh melalui analisis peta dan survei lapangan, sedangkan data statistik diperoleh melalui wawancara dan studi literatur.

Populasi penelitian ini terdiri dari empat jenis yaitu (1) lingkungan alami (lahan dan air/sumur warga), (2) komponen wisatawan yang mengunjungi kawasan wisata, (3) masyakat sekitar kawasan yang bekerja di sektor pariwisata dan (4) populasi informasi mengenai pengelolaan kawasan wisata yang diperoleh dari pengelola wisata.

Pengambilan sampel untuk analisis kesesuaian lahan, daya dukung kawasan, kondisi sosial ekonomi masyarakat, dan informasi mengenai pengelolaan kawasan wisata dilakukan menggunakan teknik purposive sampling. Sampel pada komponen kedua (wisatawan) dan kualitas air diambil dengan menggunakan random sampling dimana wisatawan diambil secara acak dan kualitas air diukur secara acak pada sumur-sumur warga di sekitar obyek wisata.

Analisis data menggunakan pendekatan kuantitatif dan kualitatif. Analisis kualitatif merupakan metode untuk menggali dan memahami makna dengan mengajukan pertanyaan-pertanyaan kepada individu atau sekelompok orang yang dianggap memiliki informasi yang dibutuhkan dalam penelitian (Creswell, 2010). Dalam lingkup penelitian ini analisis kualitatif digunakan untuk mengetahui kondisi sosial ekonomi masyarakat yang bekerja disektor pariwisata, pengelola kawasan wisata dan bagaimana persepsi mereka terhadap isu dan permasalahan yang ada dalam objek wisata serta analisis SWOT untuk menyusun strategi pengembangan obyek wisata.

Analisis kuantitatif merupakan metode untuk menguji teori tertentu dengan cara meneliti hubungan antarvariabel yang diukur menggunakan instrument penelitian dengan data dalam bentuk angka-angka sehingga dapat dianalisis menggunakan teknik statistik tertentu (Creswell, 2010). Dalam kajian ini, analisis kuantitatif digunakan untuk menilai indeks kesesuaian wisata (Yulianda, 2007), daya dukung kawasan wisata (Yulianda, 2007), touristic ecological footprint (TEF) untuk mengetahui jejak ekologis wisatawan (Peng dan Guihua 2007), metode scenic beauty estimation (SBE) untuk mengetahui preferensi visual wisatawan terhadap keindahan kawasan (Daniel dan Boster, 1976). Untuk menghitung komponen akomodasi pada analisis TEF di gunakan persamaaan nilai $\mathrm{ef}_{\mathrm{air}} \mathrm{rumah}$ tamu yaitu $0,000429 \mathrm{hm}^{2}$ per orang per malam (Gossling, dkk, 2002 dalam Kurniawan, 2011). Komponen transportasi menggunakan nilai ef berbagai tipe kendaraan yang digunakan adalah $2,93 \times 10^{-5} \mathrm{hm}^{2} / \mathrm{km}$ untuk pesawat jarak jauh, 3,34 $\times 10^{-5} \mathrm{hm}^{2} / \mathrm{km}$ untuk bis, $8,08 \times 10^{-5}$ $\mathrm{hm}^{2} / \mathrm{km}$ untuk taxi atau mobil (Kuo dan Yu, 2001 dalam 
Kurniawan, 2011). Referensi nilai EF sampah yang digunakan adalah kertas dan tekstil $3,98 \times 10^{-4} \mathrm{hm}^{2} / \mathrm{kg}$, sampah taman $1,69 \times 10^{-5} \mathrm{hm}^{2} / \mathrm{kg}$, sampah dapur $1,49 \times$ $10^{-5} \mathrm{hm}^{2} / \mathrm{kg}$ dan produk kayu $3,34 \times 10^{-5} \mathrm{hm}^{2} / \mathrm{kg}$ (Wiedmann, dkk, 2003 dalam Kurniawan, 2011).

\section{HASIL DAN PEMBAHASAN}

\section{Potensi dan Kondisi Sumberdaya Wisata}

Potensi perikanan yang dimiliki wilayah Kelurahan Tanjung Merdeka cenderung tidak dimanfaatkan secara optimal oleh masyarakat. Informasi yang diperoleh dari Lembaga Pemberdayaan Masyarakat Tanjung Merdeka menyatakan bahwa sebagian masyarakat meninggalkan profesi nelayan dan beralih ke sektor wisata. Peralihan profesi dari nelayan ke pelaku wisata ini dilakukan sejak pembukaan Patai Tanjung Bayang sebagai obyek wisata pesisir.

Atraksi wisata yang dapat dinikmati di pantai tersebut adalah berenang, rekreasi berkumpul bersama keluarga, berperahu dan memancing. Atraksi wisata tersebut dapat dinikmati pada tiga lokasi berbeda yang dikenal yaitu Pantai Angin Mamiri, Pantai Tanjung Bayang dan Patung Layar. Tiga lokasi dalam kawasan obyek wisata Pantai Angin Mamiri dan Tanjung Bayang ini memiliki daya tarik yang berbeda dan dapat memberikan pilihan bagi pengunjung (Gambar 1).

Hasil survei sarana dan prasarana wisata di Pantai Angin Mamiri dan Tanjung Bayang menunjukkan bahwa ketersediaan sarana prasarana wisata masih belum memadai. Sarana prasarana yang perlu untuk ditingkatkan antara lain adalah transportasi umum, toko cinderamata, menara pengawas pantai, fasilitas kesehatan, tempat sampah dan rambu-rambu peringatan untuk menjaga kebersihan. Sarana-prasarana tersebut merupakan bagian penting yang harus dipertimbangkan dalam pengembangan obyek wisata.

Salah satu parameter yang diukur dalam kajian potensi Pantai Angin Mamiri dan Tanjung Bayang untuk pengembangan pariwisata pesisir adalah kualitas air bersih. Parameter kualitas air yang diuji adalah parameter kualitas air yang dapat langsung di uji di lapangan yaitu salinitas, $\mathrm{pH}$, daya hantar listrik (DHL), dan total zat padat terlarut (TDS). Berdasarkan variabel di atas secara umum kualitas air bersih di lokasi penelitian masih sesuai dengan baku mutu air bersih menurut Peraturan Menteri Kesehatan Nomor 416 Tahun 1990 tentang syarat-syarat dan pengawasan kualitas air.

\section{Kesesuaian dan Daya Dukung Wisata}

Pengukuran dan pengamatan dilakukan di wilayah obyek wisata Pantai Angin Mamiri dan Tanjung Bayang, berdasarkan pada perbedaan tutupan lahan pada masing-masing obyek wisata dan area pemanfaatan obyek wisata. Wilayah tersebut yaitu Patung Layar, Pantai Tanjung Bayang dan Pantai Angin Mamiri. Hasil penilaian indeks kesesuaian wisata pesisir dapat dilihat pada Tabel 1.

Hasil pengukuran, pengamatan dan analisis data menunjukkan bahwa Indeks Kesesuaian Wisata kategori rekreasi di obyek wisata Patung Layar dan Pantai Angin Mamiri adalah sangat sesuai (S1), sedangkan di Pantai Tanjung termasuk kategori sesuai (S2) (Gambar 2). Tutupan lahan permukiman di sekitar obyek wisata Pantai Tanjung Bayang merupakan salah satu faktor yang berpengaruh terhadap indeks kesesuaian wisata. Kesimpulan yang dapat diambil adalah bahwa pengembangan pariwisata pesisir lebih diarahkan ke Pantai Angin Mamiri dan Patung Layar, dengan tutupan lahan alami sebagai daya tarik yang dapat menjadi modal utama untuk pengembangan pariwisata pesisir.

Daya dukung wisata yang dimaksud pada penelitian ini adalah Daya Dukung Kawasan wisata yang menunjukkan jumlah maksimum pengunjung yang secara fisik dapat ditampung di kawasan yang disediakan pada waktu tertentu tanpa menimbulkan gangguan pada alam (Yulianda, 2007).

Hasil perhitungan daya dukung kawasan wisata menunjukkan jumlah maksimum yang dapat ditampung oleh obyek wisata untuk tiap kegiatan wisata. Jumlah tersebut kemudian dibandingkan dengan jumlah maksimum wisatawan yang datang berkunjung di pantai Angin Mamiri dan Tanjung Bayang. Data jumlah pengunjung tersebut diperoleh dari Lembaga Pemberdayaan Masyarakat Tanjung Merdeka yang diestimasikan berdasarkan penerimaan retribusi karcis masuk obyek wisata. Daya dukung kawasan wisata dapat dilihat pada Tabel 2.

Jumlah maksimum wisatawan yang dapat ditampung Pantai Angin Mamiri untuk kegiatan wisata berenang dan rekreasi pantai adalah 4.256 orang/hari. Jumlah maksimum wisatawan yang dapat ditampung Pantai Tanjung Bayang untuk kegiatan wisata berenang, rekreasi pantai dan berperahu adalah 5.738 orang/hari. Pada pantai Tanjung Bayang terjadi tumpang tindih antara area untuk kegiatan wisata berenang dan berperahu. Jumlah maksimum wisatawan yang dapat ditampung Pantai Tanjung Bayang (Patung Layar) untuk kegiatan rekreasi, berenang dan memancing adalah 3.790 orang/hari. Perbandingan antara jumlah maksimum wisatawan yang dapat ditampung dengan jumlah maksimum wisatawan yang berkunjung di Pantai Angin Mamiri dan Tanjung Bayang menunjukkan daya dukung kawasan wisata dalam kondisi surplus. Kondisi surplus berarti bahwa obyek wisata masih mampu mendukung wisatawan yang 
datang berkunjung, sehingga memungkinkan untuk dilakukan kegiatan pengembangan obyek wisata untuk meningkatkan jumlah pengunjung.

Salah satu konsep daya dukung yang digunakan dalam penelitian ini adalah Jejak Ekologis Wisatwan (Touristic Ecological Footprint) yang merupakan bagian dari aspek permintaan (demand) wisatawan terhadap kawasan wisata. Touristic Ecological Footprint(TEF) menunjukkan seberapa besar jumlah lahan yang dibutuhkan oleh tiap wisatawan untuk mendukung aktivitas wisata yang dilakukan dan menyerap limbah yang dihasilkan. Variabel yang diukur dalam analisis
TEF terdiri atas makanan yang dikonsumsi, akomodasi, transportasi, dan limbah yang dihasilkan (Tabel 3).

Tabel 3. Jumlah dan Tipe Komponen TEF

\begin{tabular}{clcc}
\hline No & Tipe Komponen & EF (ha) & Rasio (\%) \\
\hline 1 & Makanan & 0,0958331979 & 96,29 \\
2 & Akomodasi & 0,0004290000 & 0,43 \\
3 & Transportasi & & \\
& Mobil & 0,0032280000 & \\
& Motor & 0,0000159158 & \\
& Total & 0,0032439158 & 3,26 \\
4 & Sampah & 0,0000209580 & 0,02 \\
& Total TEF & 0,0995270717 & 100 \\
\hline
\end{tabular}

Sumber: Analisis Data Lapangan Tahun 2015

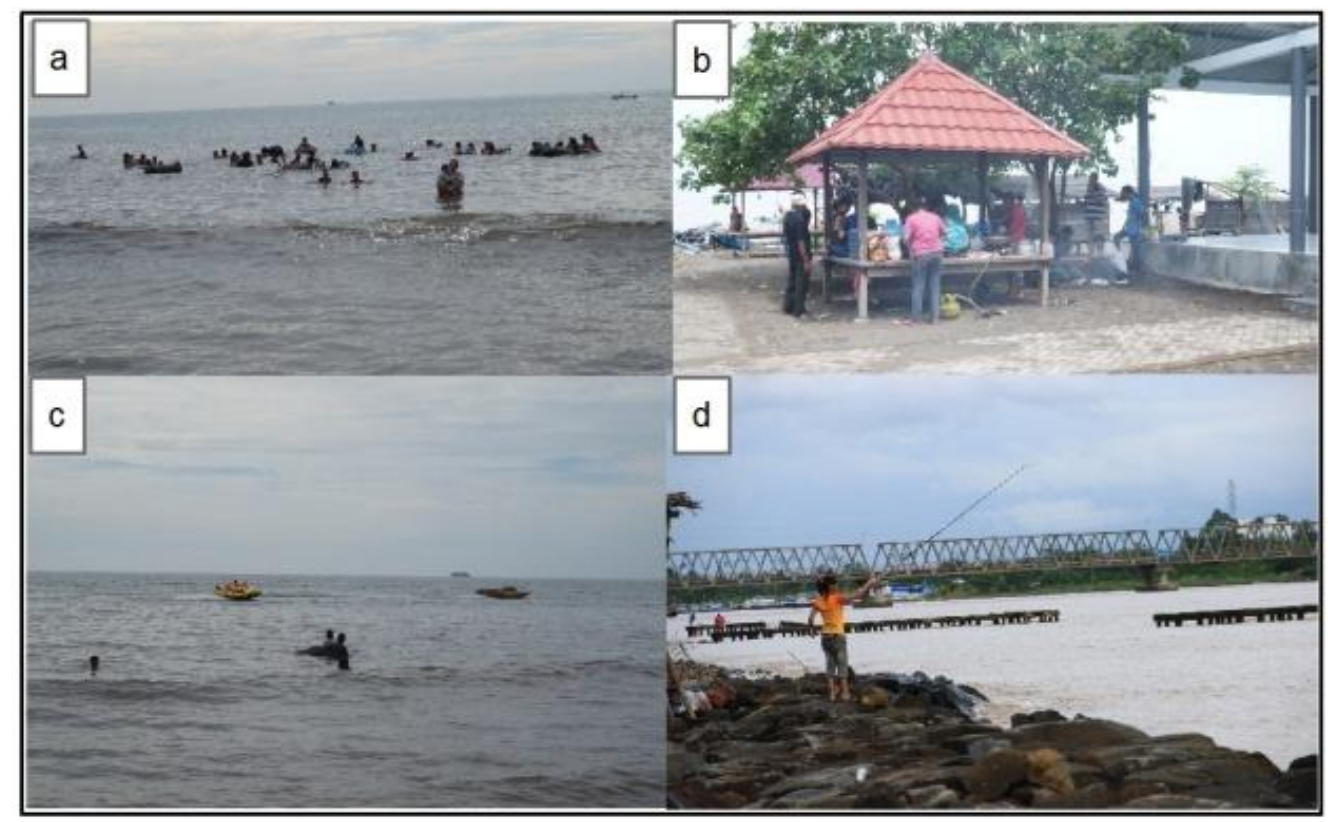

Gambar 1. Penggunaan Kawasan Wisata Pantai Angin Mamiri dan Tanjung Bayang

a) Wisata berenang di Pantai Angin Mamiri, b)Kegiatan rekreasi berkumpul bersama keluarga di Pantai Tanjung Bayang, c)Kegiatan wisata berperahu di Pantai Tanjung Bayang, dan d) Kegiatan memancing di kawasan Patung Layar (Sumber: Fadlin, 2015)

Tabel 1. Indeks Kesesuaian Wisata Pesisir

\begin{tabular}{clrr}
\hline No & Lokasi Pengukuran/Pengamatan & Skor & Indeks Kesesuaian Wisata \\
\hline 1. & Pantai Angin Mamiri & 71 & $84,52 \%$ (S1) \\
2. & Pantai Tanjung Bayang & 64 & $76,19 \%(\mathrm{~S} 2)$ \\
3. & Patung Layar (Tanjung Bayang) & 71 & $84,52 \%(\mathrm{~S} 1)$ \\
\hline
\end{tabular}

Sumber: Analisis Data Lapangan (2015)

Tabel 2. Daya dukung kawasan wisata

\begin{tabular}{cclc}
\hline No & \multicolumn{1}{c}{ Lokasi } & Jenis Kegiatan Wisata & Daya Dukung Kawasan (Orang/hari) \\
\hline 1. & Angin Mamiri & Rekreasi Pantai & 1.064 \\
& & Berenang & 3.192 \\
2. & \multirow{2}{*}{ Tanjung Bayang } & Rekreasi Pantai & 989 \\
& & Berenang & 2.968 \\
& & Berperahu & 1.781 \\
3. & \multirow{2}{*}{ Patung Layar) } & Rekreasi Pantai & 847 \\
& & Berenang & 2.540 \\
& & Memancing & 403 \\
\hline
\end{tabular}

Sumber: Analisis Data Lapangan (2015) 


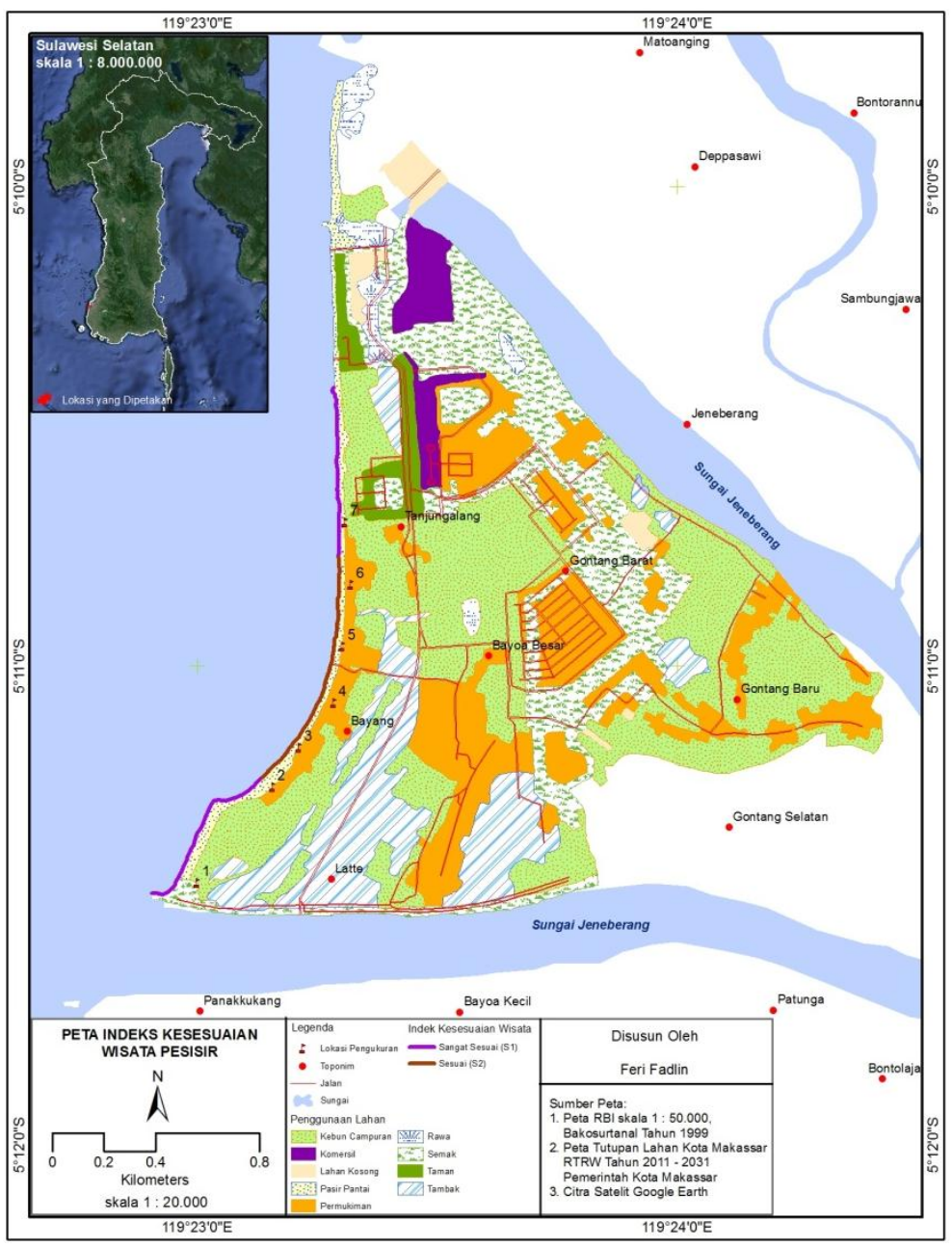

Gambar 2. Peta Indeks Kesesuaian Wisata Pesisir

Hasil analisis jejak ekologis wisatawan menunjukkan bahwa konsumsi sumberdaya terbesar wisatawan adalah pada komponen makanan yakni 96,29\%. Hasil tersebut menunjukkan bahwa konsumsi makanan wisatawan pada objek wisata Pantai Angin Mamiri dan Tanjung Bayang sangat besar. Nilai tersebut diperkirakan lebih besar 1,87 kali dari konsumsi rata-rata masyarakat perkotaan di Provinsi Sulawesi Selatan, dimana masyarakat lokal mengkonsumsi beras rata-rata 0,234 $\mathrm{kg} /$ hari/kapita dan ikan 0,086 kg/hari/kapita (Survei Sosial Ekonomi Nasional Badan Pusat Statistik Tahun 2014). Konsumsi makanan oleh masyarakat yang sangat tinggi pada obyek wisata tersebut menunjukkan bahwa peluang untuk pengembangan restoran atau rumah makan pada obyek wisata sangat besar.

\section{Kondisi Sosial Ekonomi Masyarakat Kawasan Wisata}

Informasi mengenai karakteristik sosial ekonomi masyarakat pelaku wisata diperoleh dari hasil wawancara mendalam dengan 70 informan pada obyek wisata Pantai Angin Mamiri dan Tanjung Bayang. Hasil wawancara terhadap masyarakat pelaku wisata dapat dilihat pada Tabel 4.

Masyarakat kawasan wisata Pantai Angin Mamiri dan Tanjung Bayang sangat setuju dengan rencana pengembangan obyek wisata pantai. Masyarakat menganggap Pantai Angin Mamiri dan Tanjung Bayang memiliki potensi yang baik dan akan berkembang serta membawa kemajuan bagi masyarakat utamanya dalam segi ekonomi yaitu memberikan tambahan penghasilan bagi masyarakat. Potensi yang dimiliki dan dianggap dapat memberikan dampak positif bagi kehidupan sosial ekonomi masyarakat adalahobyek dan daya tarik wisata pantai serta potensi perikanan.

Keberadaan obyek wisata Pantai Angin Mamiri dan Tanjung Bayang telah memberikan manfaat bagi masyarakat sekitar kawasan wisata. Keberadaan obyek wisata memberikan kesempatan bagi masyarakat membuka usaha berdagang dan penyediaan jasa. Kegiatan ekonomi tersebut kemudian memunculkan beberapa sarana ekonomi dan penunjang wisata antara lain kios, toko, rumah makan dan penginapan yang akan memberikan kontribusi terhadap penghasilan masyarakat. Besarnya kontribusi keberadaan obyek wisata terhadap penghasilan masyarakat sangat ditentukan oleh pengunjung atau wisatawan, sehingga pengembangan obyek wisata dengan tujuan untuk meningkatkan jumlah pengunjung perlu dilakukan. 
Kawasan obyek wisata Pantai Angin Mamiri dan Tanjung Bayang di kelola oleh Lembaga Pemberdayaan Masyarakat (LPM) Tanjung Merdeka. LPM Tanjung merdeka bertugas untuk mengelola kawasan obyek wisata menggunakan penghasilan yang diperoleh dari biaya tiket masuk dari wisatawan yang berkunjung ke obyek wisata Pantai Angin Mamiri dan Tanjung Bayang.

Kendala yang dihadapi oleh pengelola adalah masalah keterbatasan lahan. Lahan dalam kawasan obyek wisata Pantai Angin Mamiri dan Tanjung Bayang, secara keseluruhan merupakan milik pribadi, sehingga hak untuk mendirikan bangunan menjadi hak pribadi masing-masing pemilik lahan. Hak atas lahan inilah yang kemudian menjadikan masyarakat juga menarik biaya sendiri dari lahan mereka yang dimanfaatkan untuk lahan parkir, membagun penginapan, balai-balai, warung kaki lima dan toilet umum.

Pemanfaatan lahan pada obyek wisata Pantai Angin Mamiri dan Tanjung Bayang cukup tinggi dan cenderung tidak dapat diatur. Pihak pengelola mengemukakan bahwa mereka tidak dapat mengintervensi masyarakat untuk menata bangunanbangunan milik pribadi masyarakat untuk kepentingan pengembangan obyek wisata.

\section{Preferensi Visual Wisatawan}

Analisis preferensi visual wisatawan terhadap obyek wisata menggunakan metode Scenic Beauty Estimation (SBE) melalui penilaian foto dengan unit analisis pada masing-masing obyek wisata. Pengambilan foto dilakukan berdasarkan karakteristik tutupan lahan pada masing-masing obyek wisata. Berdasarkan pertimbangan tersebut, maka jumlah foto yang diambil pada penelitian ini adalah sebanyak dua belas foto. Hasil dari penilaian visual responden terhadap foto merupakan skor untuk masing-masing foto. Rata-rata skor pemberian dari setiap responden kemudian dimasukkan dalam rumus Scenic Beauty Estimation (SBE).

Hasil penilaian menggunakan metode SBE kemudian dikelompokkan menjadi kualitas estetik tinggi, sedang dan rendah berdasarkan nilai median dan standar deviasi dari keseluruhan nilai SBE foto. Rentang pengelompokkan kualitas estetik yang digunakan adalah SBE $>158,65$ untuk kualitas estetik tinggi, $22,79<\mathrm{SBE}<$ 158,65 kualitas estetik sedang dan SBE $<22,79$ untuk kualitas estetik rendah. Nilai SBE tinggi menunjukkan bahwa lanskap yang terdapat dalam foto paling banyak dipilih wisatawan sebagai lanskap yang indah, sedangkan nilai SBE rendah menunjukkan bahwa lanskap tersebut tidak disukai oleh wisatawan. Sebaran lokasi pengambilan foto dan hasil penilaian SBE masing-masing foto dapat dilihat pada Gambar 3.

Preferensi visual wisatawan terhadap lanskap obyek wisata Pantai Angin Mamiri dan Tanjung Bayang menunjukkan bahwa wisatawan cenderung menyukai lanskap di obyek wisata Tanjung Bayang khususnya disekitar Patung Layar. Kesimpulan tersebut berdasarkan nilai SBE pada lokasi di sekitar Patung Layar termasuk dalam kategori sedang hingga tinggi. Komponen penyusun elemen lanskap pada wilayah ini terdiri atas pasir pantai, semak belukar dan air pada tambak masyarakat. Nilai SBE pada Pantai Tanjung Bayang dan Angin Mamiri secara umum termasuk kategori rendah hingga sedang dengan komponen penyusun lanskap terdiri atas pasir pantai, bangunan permukiman dan semak belukar. Hasil tersebut menunjukkan bahwa wisatawan lebih menyukai kondisi lanskap obyek wisata yang masih alami.

Tabel 4. Karakteristik Sosial Ekonomi Masyarakat Sekitar Obyek Wisata

\begin{tabular}{|c|c|c|c|}
\hline No & Indikator & Kriteria & Jumlah \\
\hline \multirow[t]{3}{*}{1.} & Umur (Tahun) & Remaja $(17-25)$ & 17 \\
\hline & & Dewasa $(26-45)$ & 33 \\
\hline & & Tua $(>45)$ & 20 \\
\hline \multirow[t]{3}{*}{2.} & Tingkat Pendidikan & Akademi/Perguruan Tinggi & 8 \\
\hline & & SMP/SLTP - SMA & 49 \\
\hline & & Tidak sekolah - SD & 13 \\
\hline \multirow[t]{4}{*}{3.} & Pekerjaan & Penyedia Jasa Wisata & 45 \\
\hline & & Pedagang & 19 \\
\hline & & Nelayan & 2 \\
\hline & & Lainnya & 4 \\
\hline \multirow[t]{2}{*}{4.} & Asal & Penduduk sekitar & 63 \\
\hline & & Penduduk pendatang & 7 \\
\hline \multirow[t]{3}{*}{5.} & Pendapatan rumah tangga (Rp) & $>3.500 .000$ & - \\
\hline & & $1.900 .000-3.500 .000$ & 10 \\
\hline & & $<1.900 .000$ & 60 \\
\hline
\end{tabular}

Sumber: Analisis Data Hasil Wawancara (2015) 
Penilaian oleh wisatawan juga dilakukan terhadap kerapihan dan kebersihan pantai. Penilaian kerapihan dan kebersihan pantai berdasarkan kriteria karakteristik lanskap obyek wisata yang ditampilkan melalui foto. Metode analisis yang dilakukan terhadap penilaian kerapihan dan kebersihan pantai adalah metode analisis statistik sederhana dengan merata-ratakan penilaian kerapihan dan kebersihan oleh seratus responden dari wisatawan. Hasil penilaian kerapihan dan kebersihan tersebut dapat dilihat pada Tabel 5 .
Hasil penilaian kerapihan dan kebersihan Pantai Angin Mamiri dan Tanjung Bayang menunjukkan bahwa obyek wisata termasuk dalam kategori rendah hingga tinggi dalam hal kerapihan dan kebersihan obyek wisata. Kesimpulan yang dapat diambil bahwa kondisi obyek wisata masih memerlukan penataan dan pemeliharaan kebersihan dalam merencanakan proses pengembangannya. Kondisi kerapihan dan kebersihan sangat penting untuk menunjang estetika obyek wisata dan kenyamanan pengunjung dalam melakukan aktivitas wisata.

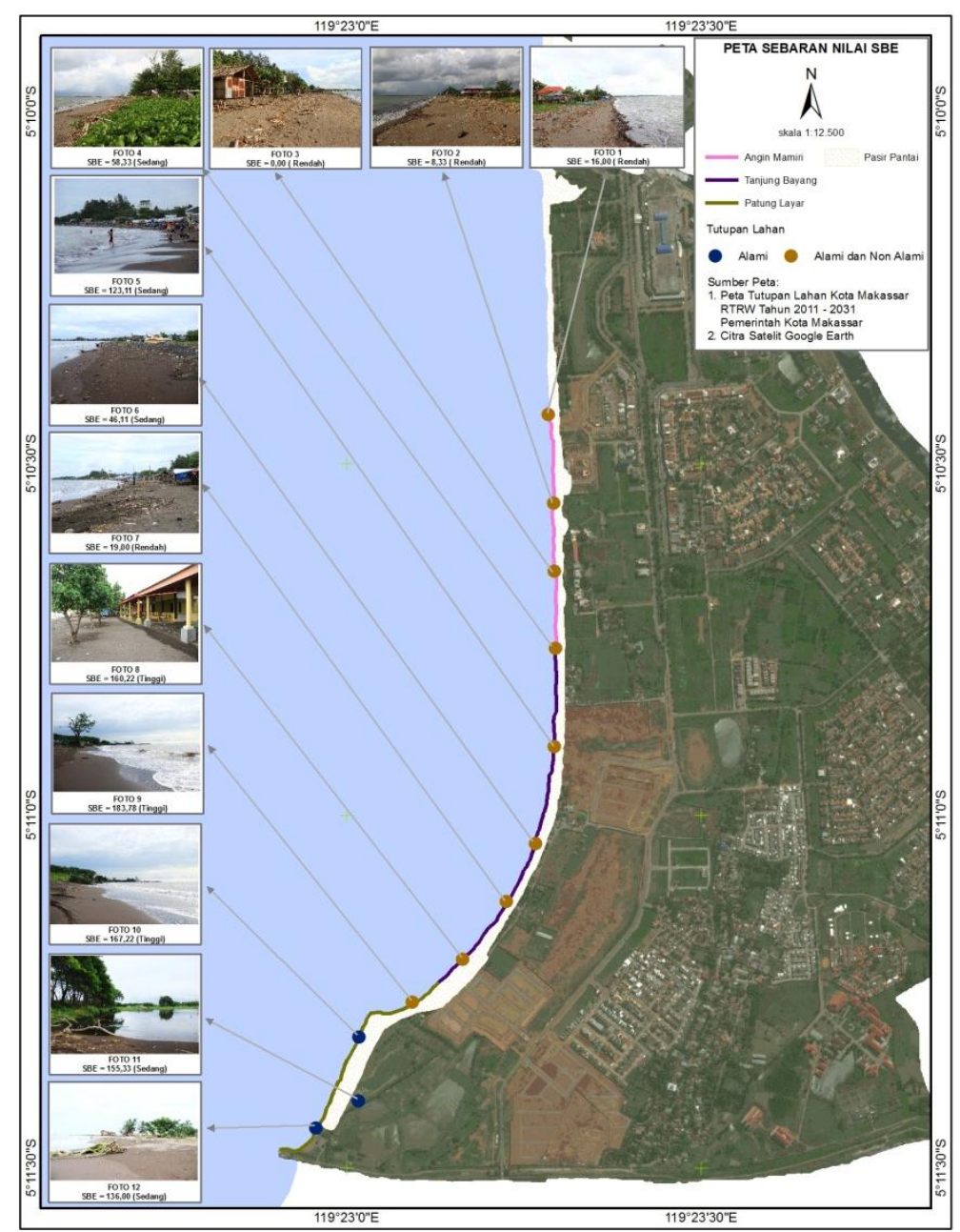

Gambar 3. Peta Sebaran Nilai SBE Pantai Angin Mamiri dan Tanjung Bayang

Tabel 5. Hasil Penilaian Kerapihan dan Kebersihan Obyek Wisata

\begin{tabular}{|c|c|c|}
\hline Kategori & Foto Lanskap & Karakteristik \\
\hline $\begin{array}{c}1 \\
\text { (Rendah) }\end{array}$ & $1,2,3,7$ & $\begin{array}{l}\text { a. Vegetasi tidak tertata dengan baik } \\
\text { b. Penataan bangunan (balai-balai, warung, penginapan dll) tidak baik } \\
\text { c. Terdapat sampah/limbah di pasir pantai dan perairan laut }\end{array}$ \\
\hline $\begin{array}{c}2 \\
\text { (Sedang) }\end{array}$ & $4,6,11,12$ & $\begin{array}{l}\text { a. Vegetasi tertata dengan cukup baik } \\
\text { b. Penataan bangunan cukup baik } \\
\text { c. Tidak terdapat sampah/limbah pada pasir pantai dan perairan laut }\end{array}$ \\
\hline $\begin{array}{c}3 \\
\text { (Tinggi) }\end{array}$ & $5,8,9,10$ & $\begin{array}{l}\text { a. Vegetasi tertata dengan sangat baik } \\
\text { b. Penataan bangunan sangat baik } \\
\text { c. Tidak terdapat sampah dan limbah pada pasir dan perairan laut }\end{array}$ \\
\hline
\end{tabular}

Sumber: Analisis Kuisioner Penelitian 


\section{Strategi Pengembangan}

Strategi pengembangan wisata pesisir Pantai Angin Mamiri dan Tanjung Bayang disusun dengan menggunakan metode analisis SWOT secara kualitatif sebagai dasar dalam merekomendasikan strategi pengembangan kawasan wisata (Rangkuti 2009, dalam Handayani 2010). Analisis SWOT diawali dengan membuat matrik faktor internal (kekuatan, kelemahan) dan eksternal (peluang, ancaman) terkait pengembangan obyek wisata. Faktor internal dan eksternal pengembangan obyek wisata diambil berdasarkan hasil kajian terhadap kondisi dan potensi sumberdaya pesisir, kondisi sosial ekonomi masyarakat serta preferensi visual wisatawan. Berdasarkan hasil analisis SWOT (Tabel 6) dihasilkan delapan rekomendasi strategi pengembangan obyek wisata Pantai Angin Mamiri dan Tanjung Bayang.

Strategi pertama, kedua dan ketiga merupakan strategi strength-opportunities (SO) yaitu strategi progresif yang disusun dengan meggunakan kekuatan untuk memanfaatkan peluang. Penjabaran strategi pertama dapat dilakukan dengan memanfaatkan potensi kesesuaian lahan, daya dukung yang memadai, serta potensi perikanan uuntuk pengembangan obyek dan daya tarik atau kegiatan wisata. Penjabaran strategi kedua adalah pemanfaatan dukungan pemerintah, keberadaan organisasi kemsayarakatan (LPM Tanjung Merdeka), serta dukungan masyarakat untuk menjalin koordinasi dan kerjasama yang baik dalam mengembangkan obyek wisata. Penjabaran strategi ketiga adalah pemanfaatan peluang obyek wisata yang sudah cukup dikenal dengan letak yang strategis untuk mempromosikan obyek dan atraksi wisata yang akan dikembangkan. Promosi ini juga bertujuan untuk menarik jumlah wisatawan yang akan berkunjung ke obyek wisata Pantai Angin Mamiri dan Tanjung Bayang.

Tabel 6. Analisis Strengths-Weakness-Opportunities-Threats (SWOT)

\begin{tabular}{|c|c|c|}
\hline Faktor Internal & $\begin{array}{l}\text { Strengths }(\mathrm{S}) \\
\text { 1. Potensi sumberdaya alam dan lingkungan } \\
\text { 2. Kesesuaian lahan dan keindahan lanskap } \\
\text { alami obyek wisata } \\
\text { 3. Letak lokasi yang strategis } \\
\text { 4. Dukungan motivasi dan partisipasi } \\
\text { masyarakat }\end{array}$ & $\begin{array}{l}\text { Weakness }(\mathrm{W}) \\
\text { 1. Sarana dan prasarana kawasan wisata serta } \\
\text { aksesibilitas kurang mendukung } \\
\text { 2. Pengelolaan oleh LPM Tanjung Merdeka } \\
\text { belum optimal } \\
\text { 3. Pengelolaan limbah belum terlaksana } \\
\text { 4. Kerapihan dan kebersihan pantai } \\
\text { 5. Kualitas sumberdaya manusia masih rendah }\end{array}$ \\
\hline $\begin{array}{l}\text { Opportunities }(\mathrm{O}) \\
\text { 1. } \\
\text { Dukungan dari } \\
\text { pemerintah Kota } \\
\text { Makasssar }\end{array}$ & $\begin{array}{l}\text { Strategi SO } \\
\text { 1. Memanfaatkan sumberdaya alam dan } \\
\text { lingkungan secara optimal dalam } \\
\text { pengembangan obyek wisata dan atraksi } \\
\text { wisata } \\
\text { 2. Meningkatkan kerjasama dan koordinasi } \\
\text { antara pemerintah Kota Makassar, LPM } \\
\text { Tanjung Merdeka, dan masyarakat dalam } \\
\text { pengembangan obyek wisata } \\
\text { 3. Letak obyek wisata yang strategis dan } \\
\text { keberadaannya yang sudah cukup dikenal } \\
\text { menjadi peluang untuk mempromosikan } \\
\text { kegiatan dan atraksi wisata yang } \\
\text { dikembangkan di Pantai Angin Mamiri dan } \\
\text { Tanjung Bayang. }\end{array}$ & $\begin{array}{l}\text { Strategi WO } \\
\text { 1. } \\
\text { Mengoptimalkan kerjasama antara LPM } \\
\text { Tanjung Merdeka dan Pemerintah dalam } \\
\text { pengelolaan limbah, peningkatan aksesibilitas } \\
\text { serta pembangunan sarana prasarana } \\
\text { penunjang wisata dengan tetap } \\
\text { memperhatikan kelestarian dan kebersihan } \\
\text { lingkungan pantai. } \\
\text { 2. } \\
\text { Memanfaatkan dukungan pemerintah dalam } \\
\text { meningkatkan kualitas sumberdaya manusia } \\
\text { sejalan dengan adanya program } \\
\text { pengembangan destinasi wisata yang } \\
\text { merupakan perpaduan antara potensi dan } \\
\text { atraksi wisata. }\end{array}$ \\
\hline $\begin{array}{l}\quad \text { Threats }(\mathrm{T}) \\
\text { 1. Kerusakan } \\
\text { lingkungan akibat } \\
\text { dampak kegiatan } \\
\text { pengunjung dan } \\
\text { limbah masyarakat } \\
\text { 2. Status kepemilikan } \\
\text { lahan }\end{array}$ & $\begin{array}{l}\text { Strategi ST } \\
\text { 1. Melibatkan masyarakat dalam pengawasan } \\
\text { dan pengelolaan limbah hasil kegiatan } \\
\text { wisata dan limbah masyarakat untuk } \\
\text { menjaga kelestarian lingkungan obyek } \\
\text { wisata } \\
\text { 2. Membentuk badan khusus yang } \\
\text { beranggotakan masyarakat, pemerintah dan } \\
\text { pihak pengelola untuk pengawasan kegiatan } \\
\text { pembangunan di kawasan wisata. }\end{array}$ & $\begin{array}{l}\text { Strategi WT } \\
\text { 1. Meningkatkan pengawasan dan pengendalian } \\
\text { dalam pemanfaatan lahan di dalam kawasan } \\
\text { wisata untuk menghindari kerusakan } \\
\text { sumberdaya kawasan wisata Pantai Angin } \\
\text { Mamiri dan Tanjung Bayang. }\end{array}$ \\
\hline
\end{tabular}


Strategi keempat dan kelima merupakan strategi weakness-opportunities (WO) yaitu strategi yang disusun dengan meminimalkan kelemahan untuk memanfaatkan peluang. Kelemahan yang diidentifikasi yaitu sarana dan prasarana wisata serta aksesibiltas yang masih kurang, pengelolaan yang belum optimal, pengelolaan limbah yang belum terlaksana, kerapihan dan kebersihan pantai yang kurang serta kualitas sumberdaya manusia yang rendah.

Dukungan dari pemerintah dapat dimanfaatkan untuk membangun sarana prasarana wisata serta aksesibilitas menuju obyek wisata, kerjasama dalam pengelolaan limbah untuk memperoleh kondisi obyek wisata yang rapih, bersih dan nyaman bagi pengunjung serta peningkatan kualitas sumberdaya manusia.

Strategi keenam dan ketujuh adalah strategi strengths-threats (ST) yaitu strategi yang disusun dengan menggunakan kekuatan untuk mengatasi ancaman. Ancaman yang diidentifikasi yaitu kerusakan lingkungan serta status kepemilikan lahan. Dukungan, motivasi dan partisipasi masyarakat dapat dimanfaatkan dalam pengawasan dan pengelolaan limbah hasil kegiatan wisata untuk meminimalisir kerusakan lingkungan. Status kepemilikan lahan menjadi ancaman sebab hak atas lahan menjadikan masyarakat kawasan wisata tidak dapat diatur dalam hal pembangunan pada lahan mereka. Pembentukan badan khusus yang beranggotakan unsur masyarakat, pihak pengelola dan pemerintah dapat menjadi solusi untuk pengawasan kegiatan pembangunan dalam kawasan wisata.

Strategi terakhir atau yang kedelapan adalah strategi weakness-threats (WT). Strategi WT merupakan strategi bertahan dengan meminimalkan kelemahan untuk menghindari ancaman. Kelemahan yang ada yang berkaitan dengan ancaman adalah pengelolaan limbah yang belum terlaksana serta kinerja LPM selaku pengelola yang belum optimal. Strategi yang dapat dilakukan untuk menghindari ancaman kerusakan lingkungan adalah dengan meningkatkan kinerja pengelola dalam hal ini LPM Tanjung Merdeka dalam pengawasan dan pengendalian pemanfaatan lahan di dalam kawasan wisata melalui sosialisasi atau forum diskusi bersama dengan masyarakat sekitar yang merupakan pemilik lahan dalam kawasan wisata.

\section{KESIMPULAN}

1. Pantai Angin Mamiri dan Tanjung Bayang memiliki potensi sumberdaya pesisir yang terdiri atas perikanan, air bersih, serta panorama pantai berpasir pada Pantai Angin Mamiri, Tanjung Bayang dan Patung Layar. Potensi kesesuaian lahan berdasarkan Indeks Kesesuaian Wisata pesisir adalah Sangat Sesuai (S1) pada Pantai Angin Mamiri dan Patung
Layar serta Sesuai (S2) pada Pantai Tanjung Bayang dengan kondisi daya dukung yang masih memadai untuk dilakukan kegiatan pengembangan.

2. Kondisi sosial ekonomi masyarakat yang bekerja di sektor wisata dilihat dari tingkat pendidikan masih tergolong rendah, yakni rata-rata menamatkan jenjang Sekolah Menengah Pertama dan Sekolah Menengah Atas. Tingkat partisipasi mayarakat dalam kegiatan wisata tinggi dengan sebagian besar tenaga kerja bersal dari penduduk sekitar. Pendapatan rumah tangga masayarakat yang bekerja di sektor wisata termasuk dalam kategori rendah dan masyarakat mendukung dan akan ikut berpartisipasi dalam kegiatan pengembangan obyek wisata Pantai Angin Mamiri dan Tanjung Bayang.

3. Preferensi visual lanskap wisatawan terhadap obyek wisata bervariasi berdasarkan kualitas estetika, kerapihan serta kebersihan pantai. Preferensi visual wisatawan terhadap kualitas estetika lanskap obyek wisata adalah kualitas estetik sedang hingga tinggi yang tersebar di wilayah Patung Layar dengan karakteristik lanskap alami berupa pantai berpasir dan semak belukar. Kualitas estetika rendah hingga sedang tersebar pada Pantai Angin Mamiri dan Tanjung Bayang dengan karakteristik lanskap berupa bangunan permukiman, balai-balai serta pasir pantai. Pereferensi visual wisatawan terhadap kerapihan dan kebersihan pantai menghasilkan penilaian rendah utamnya pada Pantai Angin Mamiri, serta sedang dan tinggi pada Tanjung Bayang dan Patung Layar. Berdasarkan preferensi visual wisatawan tersebut maka Patung Layar memiliki potensi tertinggi untuk dikembangkan dengan tetap mempertahankan lingkungan alaminya, serta diperlukan penataan dan pemeliharaan pada Pantai Angin Mamiri dan Tanjung Bayang untuk pengembangannya.

4. Strategi pengembangan obyek wisata Pantai Angin Mamiri dan Tanjung Bayang yaitu (1) pemanfaatan sumberdaya alam dan lingkungan secara optimal,(2) peningkatan kerjasama dan koordinasi antara pemerintah Kota Makassar, LPM Tanjung Merdeka dan masyarakat, (3) promosi obyek dan kegiatan wisata, (4) mengoptimalkan kerjasama antara LPM Tanjung Merdeka dan Pemerintah dalam pengelolaan limbah, peningkatan aksesibilitas serta pembangunan sarana prasarana penunjang wisata, (5) mengoptimalkan dukungan pemerintah dalam meningkatkan kualitas sumberdaya manusia, (6) melibatkan masyarakat dalam pengawasan dan pengelolaan limbah, (7) pembentukan badan khusus yang beranggotakan masyarakat, pemerintah dan pihak pengelola untuk pengawasan kegiatan 
pembangunan di kawasan wisata dan (8) peningkatan pengawasan dan pengendalian dalam pemanfaatan lahan di dalam kawasan wisata untuk menghindari kerusakan sumberdaya kawasan wisata Pantai Angin Mamiri dan Tanjung Bayang.

\section{DAFTAR PUSTAKA}

Badan Pusat Statistik. (2014). Survei Sosial Ekonomi Nasional, Konsumsi Masyarakat Perkotaan Wilayah Provinsi Sulawesi Selatan.

Creswell, J. W. (1994). Research Design Qualitative and Quantitave Approaches. London dan New Delhi: Sage Publications.

Daniel, T.C., dan Boster, R.S. (1976). Measuring Landscape Aesthetics: The Scenic Beauty Estimation Method. USDA Forest Service Research Paper RM167.

Gossling S, Hansson C B, Horstmeier O, et al. Ecological Footprint Analysis As A Tool To Assess Tourism Sustainability. Ecological Economics.

Gunawan, T., Santosa, L. W., Muta'ali, L., dan Santosa, S. H. (2005). Pedoman Survey Cepat Terintegrasi Wilayah Pesisir. Yogyakarta: Bakosurtanal - UGM.

Handayani, O. (2010). Kajian Sumberdaya Pesisir untuk Pengembangan Wisata Pantai Cerocok Painan, Kabupaten Pesisir Selatan Sumatera Barat. Skripsi. Fakultas Perikanan dan Ilmu Kelautan. Bogor: Institut Pertanian Bogor.

Hall, C.M. (2001). Trends in Ocean and Coastal Tourism. New Zealand: Department of Tourism,
Otago School, University of Otago. El Sevier Science Ltd.

Honey, M., dan Krantz, D. (2007). Global Trends in Coastal Tourism. Washington: Stanford University and Center on Ecotourism and Sustainable Development.

Khakhim, N. (2008). Analisis Preferensi Visual Lanskap Pesisir Daerah Istimewa Yogyakarta untuk Pengembangan Pariwisata Pesisir Menuju Pengelolaan Wilayah Pesisir Berkelanjutan. Disertasi. Bogor: Fakultas Perikanan dan Ilmu Kelautan Institut Pertanian Bogor.

Kurniawan, F. (2011). Pemanfaatan Sumberdaya Pulau Kecil Untuk Wisata Berkelanjutan; Studi Kasus Pulau Sepanjang, Kabupaten Sumenep Propinsi Jawa Timur. Tesis. Bogor: Institut Pertanian Bogor.

Peng, L., Guihua, Y. (2007). Ecological Footprint Study on Tourism Itinerary Products in Shangri-La, Yunnan Province, China. El Sevier Science Ltd.

Peraturan Menteri Kesehatan Nomor 416 Tahun 1990 Tentang Syarat-syarat dan Pengawasan Kualitas Air.

Yulianda, F. (2007). Ekowisata Bahari Sebagai Alternatif Pemanfaatan Sumberdaya Pesisir Berbasis Konservasi. Seminar Sains 21 Februari pada Departemen Manajemen Sumberdaya Perairan. Bogor: Institut Pertanian Bogor.

Yunus, H.S. (2010). Metodologi Penelitian Wilayah Kontemporer. Yogyakarta: Pustaka Pelajar. 